\title{
17. Detection of Measles Virus in Egg Culture and Studies on the Prophylactic Inoculation with Living Measles Virus
}

\author{
By Tenji Taniguchi and Yoshiomi OKuno \\ Institute for Microbial Diseases, Osaka University \\ (Comm. by Y. Kotake, M.J.A., Jan. 12, 1956)
}

Forty years have elapsed since Anderson and Goldberger ${ }^{1)}$ first proved that measles is a virus disease by successfully infecting monkeys with a Berkefeld filtrate of patients blood. But progress in the study of the measles virus has lagged in comparison with other virus diseases owing to the difficulty in conducting animal experiments and cultivating the virus.

On the basis of the studies of Rake et al., ${ }^{2-6)}$ it has been considered that measles virus could be successfully cultivated, to a certain extent in eggs. From our studies, however, it has been found that determination of virus multiplication in the culture is extremely difficult. Enders ${ }^{7}$ said in 1954, in his paper on the tissue culture of measles virus that "Since 1943, when the last of the communications by Rake and his collaborators appeared, no important progress has been made in the study of the etiology of measles". It is extremely difficult to determine whether virus multiplication has taken place in the culture even if the egg or the tissue culture method is used. The tests so far made for multiplication in the culture have consisted mainly of inoculation in man or monkey.

It has been shown by Rake et al. ${ }^{4)}$ that the pathogenicity of the measles virus is markedly reduced by passage through egg culture. We too have found that inoculation of egg culture virus in man and monkey results in only a very slight subclinical or inapparent infection and the conclusion was reached that it was impossible to determine virus multiplication in egg cultures by the methods of reinfection in man and monkey. ${ }^{839)}$

Rake et al. have conducted tests of the production of immunity as an aid in determining multiplication of virus in the culture. The present authors found that determination of multiplication in the egg culture was impossible by this method.

As there is no distinctive change showing viral multiplication, such as a special reaction or specific morphological change in infected eggs, an investigation was made of a method for determining multiplication of virus in egg cultures as the preliminary step.

The method for determining propagation of unknown viruses, that is, the interference phenomenon was investigated. A hemagglutinating virus was used as the challenge virus and the interference phenomenon examined in the egg cultures of measles material. Two 
types of egg cultures, an interference positive and an interference negative types, could be differentiated. That is, in the positive cases growth of the challenge virus was inhibited, while on the other hand, in the negative case there is full growth of the challenge virus. From our experience ${ }^{1011}$ ) in other types of virus, it is suggested that a positive interference phenomenon indicates multiplication of the interfering virus while in the negative case, these is no multiplication.

In order to clarify whether the agent giving rise to the interference phenomenon was the measles virus or not, convalescent serum was added to the culture to examine if neutralization of the interference phenomenon took place. As anticipated, there was neutralization of the phenomenon.

Next, the positive culture material was used as an antigen and the complement fixation reaction with immune measles serum examined and it was found that a positive reaction was obtained. It was therefore concluded that when the interference phenomenon is positive, there is propagation of virus in the egg culture.

Methods of Examination for Interference. Materials: Interfering virus: The blood or nasopharyngeal washings of a measles patients shortly after onset, or the blood of experimentally infected monkey about 10 days after inoculation was inoculated into the chorioallantoic membrane of six-day-eggs and incubated for 5 days at $35^{\circ} \mathrm{C}$ (1st passage), or serially egg-passaged virus was used as the interfering virus. For serial passage in eggs, the chorioallantoic membrane of the inoculated egg is emulsified with allantoic fluid, centrifuged, and the supernate used.

Challenge virus: Various hemagglutinating viruses were tested in the preliminary investigation, and the mumps virus found to be best suited. The virus was inoculated into the amniotic cavity of 6-day-eggs, incubated for 96-120 hours and the amniotic fluid used as the challenge virus.

Interference method: 0.2 cc of interfering virus was inoculated into the chorioallantoic cavity or allantoic membrane of the 6-dayeggs and incubated for about 96 hours at $35^{\circ} \mathrm{C}$, after which $0.1 \mathrm{cc}$ of the challenge virus was inoculated into the allantoic cavity. The egg was incubated for further $3-4$ days at $35^{\circ} \mathrm{C}$. The allantoic fluid was then taken and the chicken cell agglutination (CCA) examined.

The results were judged by comparing them with the CCA values obtained in the untreated control inoculated with the challenge virus under the same conditions as the interfering-virus-inoculatedegg. A decision of interference phenomenon positive was made when the CCA value of the test sample was at least four times lower than that of the control. When the CCA value was equal to it, the result was considered negative. To obtain the average value, 
the allantoic fluid from more than 5 eggis was pooled.

Results: Of 60 cases isolated from measles material by egg culture and examined with the interference phenomenon, 21 cases (approx. 1/3) were positive, 12 cases were questionable, and 27 cases (approx. 1/2) were negative. Variations in the degree of interference phenomenon were, of course, found among the positive cases, but in some, a reaction which was weakly positive at first became strongly positive following serial passage.

There was a general tendency for the reaction to become weaker with consecutive passages. At the present time, a positive reaction has been obtained is 19 consecutive passages at the longest.

A constant relationship between the positive and negative examples is maintained and the negative cases remain negative throughout while the positive strains gradually become negative.

When the interfering virus is obtained from the measles patient, there is a close relationship to the day of illness, and material obtained early after onset may be positive while that at a later stage will be negative in the same patient.

For example, in the case of the patient Yoshida, the Yoshida strain isolated from nasopharyngeal washings two days prior to appearance of the Koplik's spot and the day of appearance of the rash were interference phenomenon positive while that cultured two days after the appearance of the rash was negative.

Neutralization of Interference Phenomenon with Convalescent Serum of Measles. The interference phenomenon was examined on the assumption that if measles virus multiply in the egg culture, the interference phenomenon would become positive. This was based on the authors' previous results obtained on the interference phenomenon between Japanese B encephalitis virus and influenza virus, Rift Valley fever virus and H.V.J. (hemagglutinating virus of Japan), and poliovirus and mumps virus.

In order to clarify whether the virus which was cultured was actually the measles virus, serologically specific methods must be used. Therefore, neutralization tests of interference phenomenon were first conducted with convalescent measles serum.

Method: To $0.5 \mathrm{cc}$ interfering virus was added $0.5 \mathrm{cc}$ of monkey convalescent serum (20 days after inoculation with 2nd generation of monkey measles) and reacted for 1 hour at room temperature and then for 1 hour in the refrigerator. The mixture was then inoculated into the allantoic cavity of 6-day-eggs and incubated for 4 days at $35^{\circ} \mathrm{C}$. The challenge virus (mumps virus) was then added allantoically and incubated 4 days more at $35^{\circ} \mathrm{C}$. The CCA value of the allantoic fluid was determined.

As anticipated it was proven by the interference phenomenon that the culture virus was neutralized by the convalescent serum. 
Complement Fixation Reaction using Measles Virus of Egg Culture as Antigen. From the results of the neutralization tests it was believed that the interfering agent was the measles virus. With this virus as an antigen, a study was made of the complement fixation reaction against convalescent monkey serum and it was found that a specific positive reaction could be obtained. The belief by the authors that the interference positive virus in egg cultures is the measles virus was strengthened by this finding.

Method: Antigen: Various centrifuge fractions of the egg cultured, interference phenomenon positive strains.

Serum: Convalescent serum of experimentally infected measles monkey.

Complement: Normal guinea pig serum.

Hemolytic system: Sensitised ox blood cells.

As shown in the above experiments, we have succeeded in determining multiplication of measles in the developing eggs by the interference phenomenon against hemagglutinating virus (mumps virus), interference phenomenon neutralization reaction by convalescent measles serum and the complement fixation reaction.

Prophylactic Inoculation of Measles by Egg-Cultured Living Virus. Rake et al. (1939-1943) stated that they succeeded in cultivating measles virus in developing eggs and inoculation of this culture to monkey or man resulted in a light infection and showed some degree of prophylactic immunization. A summarization of their results (Maris, 1949) ${ }^{12)}$ showed that out of 479 cases inoculated, $330(69 \%)$ were infected while in the uninoculated control group 44 out of 50 became infected.

Our studies in nearly 1000 persons showed no canstant result; in some cases the effect was fairly satisfactory, but in the others the results were quite opposite, e.g., the rate of infection was higher in the inoculated groups.

The conclusion was then reached that the variation in the results was due to the use of egg cultures, regardless of whether there was proliferation of virus or not. Thus, egg cultures may be divided into two groups, one comprising egg cultures which show virus proliferation, according to the method of determination described, and the other comprising those which do not show virus proliferation. Prophylactic inoculations were given in both cases. In the first test 27 children who had not been infected with measles previously were divided into 2 groups. Group 1, consisting of 14 cases, was inoculated with living interference phenomenon positive material, and Group 2, 13 children, was given interference negative material. Inoculation was by the nasal dropping method. This method was used as it was found in our experiments in the monkey that measles can be easily infected by inhalation. The measles season started a month later and it was found that 9 out of 13 cases inoculated with the negative material were infected while not a 
single case became infected in the positive material inoculated cases.

In the second study, in another area, 33 children were inoculated with the positive material. After 6 months, when the measles season was over, it was found that only 1 case of measles had occurred while the other 32 children were found to have been spared. On the other hand, 53 out of 88 uninoculated children came down with measles.

The vaccine used by the authors was prepared by culturing measles material in the developing egg, verifying proliferation of virus by the above-mentioned interfering method, making an emulsion of the chick embryo and membranes with 10 volumes of chorioallantoic fluid and centrifuging. The supernate was used. The vaccine was stored in the frozen state and thawed before use. When lyophilized vaccine was used, distilled water was used as the solvent. Inoculation was by the nasal dropping method and a single dose of $0.1-0.3 \mathrm{cc}$ was administered.

Discussion. As stated previously, it has been shown by Rake et al. that there is reduction in pathogenicity of measles virus towards man and monkey following cultivation in developing eggs. This was also found by the present authors. The symptoms caused by this egg-adapted virus in man were so inapparent that the immunity thereby gained was at first suspected to be only apparent and accidental. It was later found, however, that proliferation of measles virus could be verified, so the belief that this was actually immunization by infection of egg cultured virus became stronger. It was believed that a form of variation (host controlled variation) may occur in the measles virus by culturing in the developing egg and the most ideal form of virus for reconvalescence immunity was obtained and vaccination could be readily performed by the simple nasal dropping method.

As the number of cases in our series is very small, a conclusion can not be made until further field works in the coming measles epidemics are made.

It is reported that, Enders and Peebles ${ }^{\text {r) }}$ succeeded in cultivating measles virus in tissue culture in July of 1954 and conducting studies on the preparation of the vaccine. The virus of measles may be cultured in tissue culture as well as in egg. It is the opinion of the present authors, however, that it is much easier to grow the virus in egg culture than in tissue culture.

For the method of preparation of vaccine and procedures for prophylactic inoculation, further research is required, but our method of prophylactic inoculation with living virus from eggs by the nasal dropping method may be most profitable.

Conclusion. 1) A method for determining proliferation of measles virus in the developing egg is described.

It is possible to clearly differentiate egg cultures in which there 
is propliferation of measles virus from those in which there is no multiplication.

2) The symptoms caused by egg-adapted measles virus in man and monkey are almost inapparent, while development of immunity against measles is recognized in inoculated individuals.

3) In repeated field works it was shown that the result of prophylactic inoculation with this living virus from eggs by nasal dropping method was excellent. As the number of cases is small, a conclusion can not be made until further experiments are conducted in future epidemics.

Acknowledgement: This study was made possible by grants from the Scientific Research Fund and Special Research Fund of the Ministry of Education.

\section{References}

1) Anderson, J. F., and Goldberger, J.,: J. Amer. Med. Assoc., 57, 113, 1621 (1911).

2) Rake, G., and Shaffer, M. F.,: Nature, 144, 672 (1939); J. Bact., 39, 40 (1940); J. Immunol., 38, 177 (1940).

3) Shaffer, M. F., Rake, G., Stokes, J. Jr., and O'Neil, G. C.,: J. Immunol., 41, 241 (1941).

4) Stokes, J. Jr., O’Neil, G. C., Shaffer, M. F., Rake, G., and Maris, E. P.,: J. Pediatrics, 22, 1 (1943).

5) Maris, E. P., Rake, G., Stokes, J. Jr., Shaffer, M. F., and O’Neil, G. C.,: J. Pediatrics, 22, 17 (1943).

6) Rake, G., Shaffer, M. F., and Jones, H. P.,: J. Infect. Diseases, 69, 65 (1941).

7) Enders, J. F., and Peebles, T. C.,: Proc. Soc. Exp. Biol. Med., 86, 277 (1954).

8) Taniguchi, T., Okuno, Y., Kamahora, J., Aoyama, A., and Kato, S.,: Med. J. Osaka Univ., 4, 381 (1954).

9) Taniguchi, T., Kamahora, J., Kato, S., and Hagiwara, K.,: Med. J. Osaka Univ., 5, 367 (1954).

10) Tsujimoto, N.,: Virus (in Japanese), 3, 50 (1953); 4, 50, 53 (1954).

11) Kusumoto, K.,: Virus (in Japanese), 5, 119 (1955).

12) Maris, E. P., Gellis, S. S., Shaffer, M. F., Dunham, W. B., Stokes, J. Jr., and Rake, G.,: Pediatrics, 4, 1 (1949). 